Article

\title{
Consumer's Surplus: An Equity Measure of High Speed Rail Investments
}

\author{
Francesca Pagliara
}

check for

updates

Citation: Pagliara, F. Consumer's Surplus: An Equity Measure of High Speed Rail Investments. Sustainability 2021, 13, 4537. https://doi.org/ $10.3390 /$ su13084537

Academic Editor: Georgina Santos

Received: 12 March 2021

Accepted: 15 April 2021

Published: 19 April 2021

Publisher's Note: MDPI stays neutral with regard to jurisdictional claims in published maps and institutional affiliations.

Copyright: (C) 2021 by the author. Licensee MDPI, Basel, Switzerland. This article is an open access article distributed under the terms and conditions of the Creative Commons Attribution (CC BY) license (https:// creativecommons.org/licenses/by/ $4.0 /)$.
Department of Civil, Architectural and Environmental Engineering, University of Naples Federico II, 80121 Naples, Italy; fpagliar@unina.it

\begin{abstract}
An economic analysis identifies, measures, and compares the costs and benefits of alternative interventions, with the objective of supporting decisions concerning the best use of limited resources. The cost benefit analysis (CBA) has played a significant role within the entire decisionmaking process, and is the principal assessment methodology. In recent years, equity issues in relation to transportation planning have become a hot topic at an international level. In this paper, the objective was to integrate equity within the evaluation of transport projects, specifically high speed rail projects. Here, consumer surplus is conceived as a monetized measure of both direct and indirect benefits for all zones, and for all socioeconomic categories served and not served by HSR, respectively. The added value of this paper is in rethinking these two shares in the computation of the total net present value as equity measures of the project itself. Specifically, the distribution of the HSR benefits among the different groups or zones in a given study area can be computed, and a comparison of the values for each zone of the study area and for each category makes it possible to assess the effects of equity between zones/categories.
\end{abstract}

Keywords: economic evaluation; cost benefit analysis; equity analysis; high speed rail

\section{Introduction}

The cost benefit analysis (CBA) plays an important role within the decision-making process, and represents the main assessment methodology in the majority of projects. In recent years, the question of equity in relation to transportation planning has become a relevant issue at an international level. In this manuscript, the focus is on the integration of equity within the transport project evaluations, specifically those related to high speed rail (HSR) projects. The consumer surplus is conceived as a monetized measure of the direct and indirect benefits for all zones, and for all socioeconomic categories served and not served by HSR, respectively. Taking into account these shares for the computation of the total net present value means considering the equity impacts of a project. This aspect is often neglected in traditional CBAs. Specifically, the distribution of HSR benefits among the different groups or zones in a given study area can be computed, and the comparison of the values for each zone of the study area and for each category makes it possible to assess the effects of equity between zones/categories.

The concept of social exclusion has its roots in France, where the term defined the rupture of the relationships between individuals and society because of the inability of the institutions to integrate individuals [1].

Recently, the question of equity related to transport systems has become an issue that governments at different territorial scales need to consider in order to seek solutions to limit the impacts.

Church et al. [2] introduced seven factors limiting the mobility of socially excluded users, namely: physical exclusion, geographical exclusion, exclusion from facilities, economic exclusion, time-based exclusion, fear-based exclusion, and space exclusion.

For Lucas [3], "transport poor users" are those who have no transport alternative suiting their physical conditions and capabilities; when the actual transport alternatives 
do not reach destinations where they can fulfill their daily activity needs; or when the weekly amount of money that is spent on transport brings the family an income that is below the poverty threshold. Moreover, it is when users are pushed to spend a long time on travel, causing time poverty and/or social isolation, and when factors like danger and safety characterize the users' travel conditions.

In many countries, it can be observed that low-income people have less transport mode choices and low-quality transport services, offering travel opportunities with little comfort and low security [4]. Vasconcellos [5] stated that traditional transport planning generates an unfair distribution of accessibility, and suggestions for new measures towards an equitable and sustainable urban environment need to be proposed. Martens [6] stated that governments should provide users with adequate transportation alternatives, with the objective of mitigating social disparities.

Banister's [7] stated that "today's transport policy benefits the rich more than the poor. But it is the better-off who are travelling faster and further, leaving the poor in the slow lane and closer to home". The poor choose to use the bus more and choose to walk more, while the rich choose to use cars and go by train. Investments in transportation systems should be more oriented to limiting this disparity—instead, they "exacerbate it!".

An economic analysis identifies, measures, and compares the costs and benefits of alternative interventions [8] to inform decisions about the best use of limited resources. Costs and benefits in economics are not necessarily measured in monetary terms, but policy makers prefer monetary values because they are a comparable common measurement unit. Economic analysis represents an important part of policy and decision-making. Many approaches to economic analyses exist, including cost-benefit, cost-effectiveness, and costminimization analyses. However, the cost-benefit analysis (CBA) is considered to be a "gold standard" for economic analysis (both costs and benefits of all options are quantified in monetary terms and compared). This is in contrast with the the cost effectiveness analysis (costs expressed in monetary terms and benefits in non-monetary terms) and with cost-minimization analysis (costs expressed in monetary terms and no attempt to measure benefits) [9].

Few examples in the published literature evaluate the equity issues in transport projects using CBA. For example, Jenkins [10] proposed an integrated financial, economic, and distributive analysis with advantages for evaluating both public sector and private sector investments. Specifically, the author identified that the role of stakeholders and how they would be as a consequence of a project was a key component in determining the likelihood of its successful implementation, as well as in motivating authorities to consider redesigning the project so that the impact on stakeholders would be more favorable. The stakeholder analysis, which was undertaken through a comparison of the economic and financial outcomes, provided an identification of the groups that were likely to promote a project, as well as those that would not favor a project. Andersson et al. [11] wrote a report for Involve, the U.K.'s leading public participation charity, where they proposed a consumer focus toolkit to understand the value of engagement by looking at the actual costs and benefits of Stakeholder Engagement. A good quality SE should be carefully designed to fit the purpose, context, and people it is intended for. The benefits could be undermined if engagement is not well planned and implemented. This toolkit shows how to build the case for engagement using monetary terms. Chambwera et al. [12] defined a stakeholder-focused CBA as an extended form of CBA that covered the private sector, public sector, households, and (where appropriate) the environment. An analytical framework was proposed, with four stakeholder groups feeding into the overall decisions about climate change adaptation interventions. The activities considered included stakeholders' engagement when analyzing the costs/benefits of an intervention, reflecting on the costs/benefits ascribed to different stakeholders in the analysis, and assessing the weight that different stakeholder groups placed on different costs/benefits. Rangarajan et al. [13] highlighted the role of SE in developing sustainable rail infrastructure systems in Missouri, USA. An SE process assessed the impact of stakeholder needs, where data 
were gathered through interviews, surveys, focus group discussions, and public meetings across the state. The main outcome of this study was that stakeholders were aware of the impact of rail services, as well as knowing about who had easy access to them. Vignetti et al. [14] provided an ex-post evaluation of ten major transport projects co-financed by the European Regional Development Fund and the Cohesion Fund between 2000-2013, located across nine EU member states. The original contribution was represented by a combination of the traditional ex-post CBA with a qualitative analysis. A retrospective CBA quantified the benefits/costs of the projects, then interviews with relevant stakeholders were undertaken in order to reconstruct the project history, discover behavioral patterns, and assess any wider non-quantifiable effects. Pagliara and Di Ruocco [15] contributed to the measurement of the costs and benefits of a participatory activity. Specifically, they integrated the costs and benefits of an SE in a CBA for a high speed rail (HSR), providing a net present value taking into account equity issues.

In Section 2 of this paper, the concept of equity is reported in relation to HSR. In Section 3, the consumer's surplus is represented as a measure of the direct and indirect benefits of a HSR project considering equity impacts, while in Section 4, conclusions and further research perspectives are described.

\section{High Speed Rail and Equity Issues}

In the last decades, several projects have been promoted to extend the HSR network in many countries around the globe. This demonstrates the main role that these systems are aiming to achieve. Investing public money in HSR deployment produces many benefits, like time saving; an increase in comfort and trips; a decrease of congestion, of accidents and of environmental externalities; and wider economic benefits [16]. However, the impact of HSR systems on equity issues has been less developed. Indeed, there are only a few studies that focus on the link between HSR systems and social exclusion. The analysis of the surveys proposed by Cass et al. [17] showed that HSR has both positive and negative social impacts. The positives impacts were increased accessibility to activities for commuting users. The negative impact was that people living far from stations or who those who could not afford the payment of a high ticket price were socially excluded and had less chance of finding better jobs.

Monzon et al. [18] approached the issue of social exclusion and HSR through a methodology based on accessibility indicators. They aimed at supporting planners in optimizing access efficiency and equity objectives in rail infrastructure investments. The main findings of this study showed that an increase of speed from $220 \mathrm{~km} / \mathrm{h}$ to $300 \mathrm{~km} / \mathrm{h}$, in a given corridor, resulted in significant negative impacts on spatial equity between locations with and without an HSR service.

The same authors proposed an assessment methodology for HSR projects following a two-fold approach, i.e., addressing the issues of both efficiency and equity. Efficiency impacts were evaluated in terms of increased accessibility resulting from the HSR project, with a focus on major urban areas. Likewise, spatial equity implications were derived from changes in the distribution of accessibility values among these urban agglomerations [19]. Ortega et al. [20] evaluated the impacts on territorial cohesion as a result of investments in HSR at different planning levels. Changes in the territorial distribution of accessibility were used to assess the effects of cohesion. Ortega et al. [21] investigated the influence of alternative spatial representations on measuring the results of territorial cohesion, focusing on HSR projects. Chen and Wei [22] stated, for the case study of the Hangzhou East Rail Station in China, that HSR was still not affordable for the majority of the population. For journeys of less than $200 \mathrm{~km}$, HSR was not competitive, as most of the new HSR stations were located outside traditional urban centers. Moreover, the stations were very large, so the interchange time inside the railway station was also high. The price of HSR was twice the price of the traditional railway, and this led to a separation of social classes. Furthermore, the expropriation of land for development led to segregation and social injustice. 
Chen and Haynes [23] stated that regional economic disparity decreased thanks to HSR. HSR improved accessibility, fostering regional economic growth in China. Yu and Yao [24] measured the income inequality level from a county level and within urban and rural areas of China. The result was that the Gini coefficient of the regional economy rose when new HSR stations became operational, meaning that the intra-regional income inequality increased. Kim and Sultana [25] studied the effects of HSR extensions on accessibility and spatial equity changes in South Korea. They showed that spatial equity degenerated as the accessibility increase was mainly felt in cities along the primary HSR corridor close to Seoul. In the papers by Pagliara et al. [26-30] and Pagliara and Biggiero [27], the seven categories of exclusion proposed by Church et al. [2] were adapted to medium-long distance trips. Three case studies were considered, i.e., Italy, the U.K., and Spain. In Italy, the geographical exclusion was the mostly felt, followed by the economic one, as in this country the HSR system serves only main cities. On the other hand, in the U.K., the ticket price was still expensive with regard to the one of the conventional rail, making the system not economically affordable for everybody. For the case study of Spain, the network was quite extended, but the economic factor was still an element of exclusion. The results obtained for Italy were confirmed by Biggiero et al. [31], who, with a joint $\mathrm{RP} / \mathrm{SP}$ survey of Italian travelers, reported the transport mode mostly chosen in a given context. The results showed that HSR and cars were the preferred travel modes for daily return journeys, and that the main type of social exclusion was the geographical one, given the limited availability of transport to and from the station. The price of the ticket, and therefore economic exclusion, was mainly felt by people with a low income.

Watson et al. [32] stated that HSR could bring benefits to society by helping improve employability, balance the economy, and bring prosperity to local communities. The results of their study showed that HSR improved accessibility, encouraged economic development, and expanded the labor market. However, in the areas between the main HSR stations, unemployment increased and the outflow of manpower to cities with HSR stations increased. Therefore, the development of HSR could widen the gap between the territorial equity, thus reducing social cohesion, leading to a polarization of differences between territories.

Delaplace [33] pointed out that the development of HSR lines could increase inequality in developing countries. In these countries, there are marked inequalities between the population, especially concerning education, health, and income, and the introduction of HSR could lead to an increase in them. Morocco was analyzed. To the South and East parts of Marrakech, the absence of a traditional railway led to inequality among the population, the introduction of a HSR service in the North-West of the country had further amplified these inequalities, and furthermore, gender inequalities implied an unequal use of HSR. Wang and Duan (2018) [34] simulated changes in territorial accessibility, spatial equity, and winner and loser cities because of the development of an HSR network in the Yangtze River Delta (YRD) in China.

Yang et al. [35] analyzed the spatial and temporal characteristics of China's transport accessibility and spatial equality through accessibility and social needs. The results of the study demonstrated that HSR improved the accessibility level of the country and promoted socio-economic exchanges between the regions, especially the central and eastern regions, which exceeded the $60 \%$ mark because of the impact of multiple HSR. Wang and Zhang (2019) [36] explored the impact of HSR on the efficiency and spatial equity within China's Central Plains Economic Region. From an equity point of view, they showed that disparities in regional accessibility increased because of the HSR service.

Ren et al. [37] analysed in what way the deployment of HSR networks could lead users' exclusion as a result of different socioeconomic categories. A survey was carried out on conventional rails leaving the city of Chongqing. The main findings showed low income passengers and those with lower levels of education chose conventional trains and felt excluded from HSR because of the high ticket prices. 
Zhan et al. [38] introduced a railway timetable, defining different tickets fares to foster low-income passenger trips. The Guangzhou-Zhuhai HS intercity rail network in China was considered, and the main results demonstrated that the framework proposed improved social equity.

Zhang et al. [39] studied the impact of HSR on the regional equity of the Chinese provinces. They demonstrated that HSR deployment increased regional economic equity because of the increase of accessibility.

Cascetta et al. [40] demonstrated that HSR in Italy had decreased equity in terms of users' travel time accessibility, while Cavallaro et al. [41] presented the spatial and social equity railway indices to estimate the travel time variations of the cities of Alessandria and Asti, in the North of Italy. The authors showed that the direct connections decreased with an increase in ticket fares.

\section{Consumer's Surplus as a Measure of Equity Impacts of High Speed Rail Projects}

The effects perceived by the users of any project related to the transport system can be calculated as the net perceived utility (or surplus) variation linked to travel choices in the project $(\mathrm{P})$ and non-project $(\mathrm{NP})$ scenarios. The computation can be carried out following two approaches based on the demand model considered, i.e., a behavioral random utility (RU) model or a descriptive one [42]. In this paper, the behavioral approach has been chosen.

Consider, for example, the choice sequence "making $x$ trips for purpose $\mathrm{s} /$ to destination $\mathrm{d} /$ with mode $\mathrm{m} /$ following path $\mathrm{k}^{\prime \prime}$, in this case, the utility $U_{P}{ }^{i}$, perceived by user $i$ in zone $o$ in the state $P$, is expressed as follows [42]:

$$
U_{P}^{i}=\sum \beta_{k} X_{k j(i)}^{i P}+\varepsilon_{j(i)}^{i}=V_{x o d m k}^{i}\left(X_{j(i)}^{P}\right)+\varepsilon_{x o d m k}^{i}
$$

where $j(i)$ represents the sequence $(x \circ d m k)$ and the vector of attributes $X^{P}{ }_{j(i)}$ take into account the level-of-service (times, costs, etc.) and other variables corresponding to $j(i)$ in the project $P$ scenario. Some attributes, $X^{i}{ }_{k j(i)}$, represent utilities and have positive signs, while others represent costs and have negative coefficients. Equation (1) is the perceived net utility or surplus.

In random utility models, the perceived utility (1) represents a random variable and the user chooses the alternative, thus maximizing its value. The impacts on the users of the transport system can be evaluated through the expected value change of the surplus perceived by all of the users with the same characteristics. This value is equal to the mean of the net utility (surplus) perceived for the alternative chosen, which is that of maximum utility. The perceived surplus mean value is then equal to the maximum perceived utility mean value among all the available alternatives, named the expected maximum perceived utility (EMPU) variable.

The attributes chosen and their corresponding coefficients, $\beta_{k}$, represented in the systematic utilities (1), depend on the trip purpose and the socioeconomic characteristics of the user. The EMPU variable of $s$ is calculated for the user of class $i$ in zone $o$, with the following expression:

$$
s_{P}(o, i)=E\left[\max _{x d m k} U_{P}^{i}(x d m k)\right]
$$

Considering the residuals $\varepsilon_{x o d m k}$ as i.i.d. Gumbel variables with parameter $\theta=1$, the EMPU (2) represents a logsum variable, as follows:

$$
s_{P}(o, i)=\ln \sum_{x d m k} \exp \left[V_{x d m k}^{i}\left(\boldsymbol{X}_{i}^{P}\right)\right]
$$

The total net utility of users of class $i$ in zone $o$ in the project state, $S_{P}(o, i)$, is equal to:

$$
S_{P}(o, i)=N_{o}^{P}(i) S_{P}(o, i)
$$


where $N^{P}{ }_{o(i)}$ represents the number of users of class $i$ in zone $o$. This number takes into account both the actual and potential users, where the potential ones are those choosing not to travel. The perceived surplus change for the users of class $i$ in zone $o$ can be expressed as follows:

$$
D S_{P}(o, i)=S_{P}(o, i)-S_{N P}(o, i)
$$

where $S_{N P}(0, i)$ is the total perceived surplus in the $N P$ scenario.

Users of different classes, in different traffic zones, can be aggregated in several ways. The perceived impact of project $P$ for the aggregate of all users is represented by the following expression:

$$
D S_{P}=\sum_{i} \sum_{o} D S_{P}(o, i)
$$

In many applications, the perceived surplus variations should be analyzed for disaggregate user groups, with the objective of highlighting the distribution of project benefits among the different groups or zones in the study area. The comparison of the values for each zone and category makes it possible to assess the effects of equity between the zones/categories.

The average perceived surplus $s_{P}(o, i)$ and the total utility changes computed with Equations (5) and (6) can be represented in dimensionless measurement units, named util. To compare them with other impacts of the project $(P)$, these values can be represented in monetary units. Indeed, they can be divided by the monetary cost coefficient, expressed in units $^{-1}$.

For the zones (cities) directly served by a HSR station, this measure represents a direct benefit and can be introduced within the computation of the costs in a CBA as follows:

$$
\text { Benefit }(€)=D S_{p} / \beta(u t i l / \epsilon)
$$

where

$$
D S_{P}=S_{P}-S_{N P}
$$

$S_{P}$ and $S_{N P}$ are the average value of the perceived surplus (satisfaction variable) equal to $N_{P} \cdot s_{P}$ and $N_{N P} \cdot s_{N P}$, respectively; $N_{P}$ and $N_{N P}$ are the total number of transport system users; and $s_{P}$ and $s_{N P}$ are the average value of the perceived surplus (satisfaction variable), and for those who are not directly served by an HSR station, but that benefit from it indirectly, as they can reach it through traditional rail lines or public transport such as buses, a measure of the indirect benefit can be computed with the same equation, but taking into account users of the HSR system and zones not directly served by an HSR station. Therefore, the above mentioned should be doubled considering these two more shares to be added in the general costs computation of any CBA in order to monetarize equity and inclusion.

\section{Conclusions and Further Research}

El Ansari and Andersson [9] stated that the "analysis of the costs and benefits of participatory activities should form part of an overall evaluation of SE". Yet, to date, such a perspective remains overlooked, despite its value and benefits to society.

This paper manages to provide a contribution regarding equity issues in relation to transport projects' economic evaluation. CBA has been criticized several times, also because of its difficulty in taking into account social justice. Some authors have suggested the inclusion of equity weights for all or some costs and benefits [42] alongside a CBA, and others have suggested a disparity analysis [43].

A new era of transportation decision-making processes should be promoted, where an equity, inclusion, and diversity analysis in the final stage of the decision-making process should be fostered. Indeed, when planning the introduction of an HSR line, policy makers and investors should focus on integrative solutions, taking into account that the gap between primary and peripheral areas should not increase, as well as making the service inclusive to all users, both directly and not directly served. 
Redirecting research towards methods of evaluation, indicators or more sophisticated methodologies for quantifying equity impacts should be considered as a watchword.

Further research will consider applications of the above methodology to a real case study. Specifically, a comparison of the NPVs with and without the equity measure should be carried out in order to see the different results.

The policy implications of this study are extremely important. Embedding this analysis in any evaluation method can result in a significant impact on the whole transport decisionmaking process, and thus on the comparison of the different alternatives. These inputs are specifically aimed at those managing, designing, delivering, and planning transport projects, taking into account equity issues, representing a useful tool for understanding and making the case for equity in an economic analysis.

Funding: This research received no external funding.

Informed Consent Statement: Informed consent was obtained from all subjects involved in the study.

Data Availability Statement: No data set has been used in this manuscript.

Conflicts of Interest: The author declares no conflict of interest.

\section{References}

1. Silver, H. Social Exclusion and Social Solidarity: Three Paradigms; International Institute for Labour Studies (IILS) 69: Genève, Switzerland, 1994.

2. Church, A.; Frost, M.; Sullivan, K. Transport and social exclusion in London. Transp. Policy 2000, 7, 195-205. [CrossRef]

3. Lucas, K. Transport poverty and inequalities. Eur. Transp. Res. Rev. 2018, 10, 17. [CrossRef]

4. Lucas, K.; Mattioli, G.; Verlinghieri, E.; Guzman, A. Transport poverty and its adverse social consequences. Proc. Inst. Civ. Eng. Transp. 2016, 169, 353-365. [CrossRef]

5. Vasconcellos, E. Urban Transport, Environment, and Equity: The Case for Developing Countries; Earthscan Publications: London, UK, 2001.

6. $\quad$ Martens, K. Transport Justice: Designing Fair Transportation Systems; Taylor \& Francis Ltd.: Abingdon, UK, 2016.

7. $\quad$ Banister, D. Inequality in Transport; Alexandrine Press: London, UK, 2018.

8. Shefer, D.; Aviram, H. Incorporating agglomeration economies in transport cost-benefit analysis: The case of the proposed light-rail transit in the Tel-Aviv metropolitan area. Pap. Reg. Sci. 2005, 84, 487-508. [CrossRef]

9. El Ansari, W.; Andersson, E. Beyond the value? Measuring the costs and benefits of public participation. J. Integr. Care 2011, 6, 45-57. [CrossRef]

10. Jenkins, G.P. Evaluation of stakeholder impacts in cost-benefit analysis. Impact Assess. Proj. Apprais. 1999, 17, 87-96. [CrossRef]

11. Andersson, E.; Fennell, E.; Shahrokh, T. Making the Case for Public Engagement. Involve Report. 2011. Available online: https://www.involve.org.uk/resources/publications/practical-guidance/making-case-public-engagement (accessed on 23 February 2021).

12. Chambwera, M.; Baulcomb, C.; Lunduka, R.; de Bresser, L.; Chaudhury, A.; Wright, H.; Loga, D.; Dhakal, A. Stakeholder-Focused Cost-Benefit Analysis in the Water Sector: A Guidance Report; International Institute for Environment and Development (IIED): London, UK, 2012. Available online: https:/ / pubs.iied.org/pdfs/16524IIED.pdf (accessed on 15 January 2021).

13. Rangarajan, K.; Long, S.; Tobias, A.; Keister, M. The role of stakeholder engagement in the development of sustainable rail infrastructure systems. Res. Transp. Bus. Manag. 2013, 7, 106-113. [CrossRef]

14. Vignetti, S.; Giffoni, F.; Pancotti, C.; Pagliara, F. Analytical framework for ex-post evaluation of transport projects: Lessons learnt on retrospective CBA. Pap. Reg. Sci. 2020, 99, 683-703. [CrossRef]

15. Pagliara, F.; Di Ruocco, I. How public participation could improve public decisions on rail investments? Reg. Sci. Policy Pr. 2018, 10, 383-403. [CrossRef]

16. Chen, C.-L.; Hall, P. The wider spatial economic impacts of high speed trains: A comparative case study of Manchester and Lille sub-regions. J. Transp. Geogr. 2012, 24, 89-110. [CrossRef]

17. Cass, N.; Shove, E.; Urry, J. Social exclusion, mobility and access. Soc. Rev. 2005, 3, 539-555. [CrossRef]

18. Monzón, A.; Ortega, E.; López, E. Social impacts of high speed rail projects: Addressing spatial equity effects. In Proceedings of the World Transport Research-12th World Conference on Transport Research, Lisbon, Portugal, 11-15 July 2010.

19. Monzón, A.; Ortega, E.; López, E. Efficiency and spatial equity impacts of high-speed rail extensions in urban areas. Cities 2013, 30, 18-30. [CrossRef]

20. Ortega, E.; López, E.; Monzón, A. Measuring territorial cohesion impacts of High-Speed Rail at different planning levels. In Proceedings of the 50th Congress of the European Regional Science Association: Sustainable Regional Growth and Development in the Creative Knowledge Economy, Jönköping, Sweden, 19-23 August 2010. 
21. Ortega, E.; López, E.; Monzón, A. Territorial cohesion impacts of high-speed rail under different zoning systems. J. Transp. Geogr. 2014, 34, 16-24. [CrossRef]

22. Chen, Z.; Haynes, K.E. Impact of high-speed rail on regional disparity in China. J. Transp. Geogr. 2017, 65, 80-91. [CrossRef]

23. Yu, W.; Yao, Y. The route of development in intra-regional income equality via High Speed Rail: Evidence from China. In Proceedings of the 2019 Agricultural \& Applied Economics Association, Annual Meeting, Atlanta, GA, USA, $21-23$ July 2019.

24. Kim, H.; Sultana, S. The impacts of high speed rail extensions on accessibility and spatial equity changes in South Korea from 2004 to 2018. J. Transp. Geogr. 2015, 45, 48-61. [CrossRef]

25. Pagliara, F.; Menicocci, F.; Vassallo, J.M.; Gomez, J. Social exclusion and High Speed Rail: The case study of spain. In Proceedings of the XII Congreso de Ingeniería del Transporte, Valencia, Spain, 7-9 June 2016.

26. Pagliara, F.; Biggiero, L. Some evidence on the relationship between social exclusion and high speed rail systems. HKIE Trans. 2017, 24, 17-23. [CrossRef]

27. Pagliara, F.; Biggiero, L.; Menicocci, F. Social Exclusion and High-Speed Rail: Some evidence from three European countries. In Transport Infrastructure and Systems, Proceedings of the AIIT International Congress on Transport Infrastructure and Systems (TIS 2017), Rome, Italy, 10-12 April 2017; Dell'Acqua, G., Wegman, F., Eds.; CRC Press: Boca Raton, FL, USA, 2017; pp. 579-585.

28. Pagliara, F.; De Pompeis, V.; Preston, J. Travel cost: Not always the most important element of social exclusion. Open Transp. J. 2017, 11, 110-119. [CrossRef]

29. Pagliara, F.; Menicocci, F.; Vassallo, J.M.; Gomez, J. Economic, geographical and time-based exclusion as main factors inhibiting Spanish users from choosing High Speed Rail. 360 Rev. Alta Velocidad 2018, 5, 369-383.

30. Biggiero, L.; Pagliara, F.; Patrone, A.; Peruggini, F. Spatial equity and High-Speed Rail system. Int. J. Transp. Dev. Integr. 2017, 1, 194-202. [CrossRef]

31. Watson, I.; Ali, A.; Bayyati, A. Social sustainability of HSR-comparative study. In Proceedings of the Stephenson Conference: Research for Railways, London, UK, 25-27 April 2017.

32. Dalaplace, M. High-speed rail in developing countries and potential inequalities of use: The case of Morocco. 360 Rev. Alta Velocidad 2018, 6, 37-59.

33. Wang, L.; Duan, X. High-speed rail network development and winner and loser cities in megaregions: The case study of Yangtze River Delta, China. Cities 2018, 83, 71-82. [CrossRef]

34. Yang, J.; Guo, A.; Li, X.; Huang, T. Study of the Impact of a High-Speed Railway Opening on China's Accessibility Pattern and Spatial Equality. Sustainability 2018, 10, 2943. [CrossRef]

35. Wang, X.; Zhang, W. Efficiency and Spatial Equity Impacts of High-Speed Rail on the Central Plains Economic Region of China. Sustainability 2019, 11, 2583. [CrossRef]

36. Ren, X.; Chen, Z.; Wang, F.; Dan, T.; Wang, W.; Guo, X.; Liu, C. Impact of high-speed rail on social equity in China: Evidence from a mode choice survey. Transp. Res. Part A Policy Pract. 2020, 138, 422-441. [CrossRef]

37. Zhan, S.; Wong, S.C.; Lo, S.M. Social equity-based timetabling and ticket pricing for high-speed railways. Transp. Res. Part. A Policy Pr. 2020, 137, 165-186. [CrossRef]

38. Zhang, F.; Yang, Z.; Jiao, J.; Liu, W.; Wu, W. The effects of high-speed rail development on regional equity in China. Transp. Res. Part. A Policy Pr. 2020, 141, 180-202. [CrossRef]

39. Cascetta, E.; Cartenì, A.; Henke, I.; Pagliara, F. Economic growth, transport accessibility and regional equity impacts of high-speed railways in Italy: Ten years ex post evaluation and future perspectives. Transp. Res. Part. A Policy Pr. 2020, 139, $412-428$. [CrossRef] [PubMed]

40. Cavallaro, F.; Bruzzone, F.; Nocera, S. Spatial and social equity implications for High-Speed Railway lines in Northern Italy. Transp. Res. Part. A Policy Pr. 2020, 135, 327-340. [CrossRef]

41. Cascetta, E. Transportation Systems Analysis: Models and Applications; Springer: New York, NY, USA, 2009.

42. Johansson-Stenman, O. Distributional Weights in Cost-Benefit Analysis-Should We Forget about Them? Land Econ. 2005, 81, 337-352. [CrossRef]

43. Wang, F. Analysis on the Regional Disparity in China and the Influential Factors. Am. Int. J. Humanit. Soc. Sci. 2016, 2, 94-104. 